\title{
USO DE PLANTAS MEDICINAIS NA ODONTOLOGIA: UMA REVISÃO INTEGRATIVA
}

\author{
* Mayra Sousa Gomes 1 \\ Angelica Kércya Pereira de Mendonça' \\ Thaís Oliveira Cordeiro "I \\ Maisie Mitchele Barbosa Oliveira III
}

\begin{abstract}
RESUMO
A fitoterapia tem ganhado espaço no meio odontológico por apresentar produtos naturais com elevada atividade terapêutica, menor toxicidade e melhor biocompatibilidade cientificamente comprovadas, quando comparados aos medicamentos convencionais. O desconhecimento sobre indicações e cuidados no uso de plantas medicinais ainda é um problema entre os profissionais de saúde. Especificamente na odontologia, essa prática tem sido pouco explorada para o tratamento de afecções bucais, ou de doenças sistêmicas com manifestações bucais. O objetivo desse estudo foi revisar e sintetizar as informações da literatura científica sobre as plantas medicinais que são mais utilizadas para os problemas da cavidade bucal, de forma a contribuir e promover o uso dessa terapia pelos cirurgiões-dentistas. 0 presente trabalho foi realizado através da revisão de literatura especializada por abordagem indutiva, por meio de técnica de documentação bibliográfica. Os fitoterápicos são capazes de contribuir para a prevenção, controle e tratamento de várias doenças bucais, podendo ser usados concomitantes a medicamentos tradicionais (alopáticos) ou não. No entanto, é importante que o profissional conheça a ação farmacológica desses compostos fitoterápicos, bem como os seus efeitos colaterais, interações medicamentosas e as contraindicações.
\end{abstract}

PALAVRAS-CHAVE: Fitoterapia. Odontologia. Patologias Bucais.

Cirurgiã-dentista. Doutoranda em Ciências Odontológicas, Universidade Federal do Rio Grande do Norte UFRN. Departamento de Odontologia. CEP: 59056-000, Natal, Rio Grande do Norte, Brasil.

*Autora-correspondente: e-mail:mayragomes89@gmail.com. Orcid: 0000-0001-7915-1618; 0000-0002-9769-9633

Cirurgiã-dentista. Mestra em Ciências Odontológicas, Universidade Federal do Rio Grande do Norte UFRN. Departamento de Odontologia. CEP: 59056-000, Natal, Rio Grande do Norte, Brasil. Orcid: 0000-0003-0078-715X

Bióloga. Doutoranda em Biotecnologia, Universidade Federal do Rio Grande do Norte, Departamento de Biofísica e Farmacologia. CEP: 59056-000, Natal, Rio Grande do Norte, Brasil. Orcid: 0000-0001-7141-3708 


\section{INTRODUÇÃO}

O uso de plantas medicinais e a fitoterapia foram implantados no Sistema Único de Saúde por meio da Política Nacional de Práticas Integrativas e Complementares, pela portaria $n^{\circ} 971$ de 2006, sendo regulamentado o exercício da fitoterapia ao cirurgiãodentista, em 2008, pelo Conselho Federal de Odontologia. ${ }^{1}$

Apesar da regulamentação do exercício da fitoterapia, o desconhecimento sobre indicações e cuidados no uso de plantas medicinais ainda é um problema entre os profissionais de saúde. ${ }^{2}$ Nascimento Júnior et al. ${ }^{3}$ observaram a necessidade de capacitação e motivação de profissionais da Estratégia de Saúde da Família (ESF) para a indicação de plantas medicinais, pois grande parte desses trabalhadores não está preparada para repassar informações sobre o uso de plantas medicinais, ou prescrever fitoterápicos para a população, o que resulta em prejuízo para o serviço, uma vez que a Medicina Complementar e Alternativa é uma boa opção e geralmente apresenta um custo menor. Especificamente na odontologia, essa prática tem sido pouco explorada para o tratamento de afecções bucais, ou de doenças sistêmicas com manifestações bucais. ${ }^{2}$

Nesse sentido, a fitoterapia tem ganhado espaço no meio odontológico por apresentar produtos naturais com elevada atividade terapêutica, menor toxicidade e melhor biocompatibilidade, cientificamente comprovadas, quando comparados aos medicamentos convencionais, além de revelar custos mais acessíveis ao público. ${ }^{4}$ Tais características fazem dessa terapia uma boa alternativa para o tratamento de problemas bucais, potencializando o uso dessa terapêutica e dando suporte aos profissionais da odontologia e seus pacientes. ${ }^{5}$

Em um país como o Brasil, que possui grande potencial para o desenvolvimento da fitoterapia, com a maior diversidade vegetal do mundo, é importante o estudo e a validação científica desse conhecimento, uma vez que o interesse popular e institucional em terapias alternativas e/ou complementares vem crescendo nos últimos anos. ${ }^{6}$

As pesquisas com plantas medicinais na odontologia buscam desenvolver produtos que apresentem substantividade, inocuidade aos tecidos bucais, redução do biofilme bacteriano, não favorecer o desenvolvimento de bactérias resistentes, não manchar os dentes e não alterar a gustação; uma vez que nenhum produto comercialmente disponível apresenta todas essas vantagens. ${ }^{5,7}$

À vista disso, o objetivo desse estudo foi revisar e sintetizar as informações da literatura científica sobre as plantas medicinais que são mais utilizadas para os problemas da cavidade bucal, de forma a contribuir e promover o uso dessa terapia pelos cirurgiões-dentistas.

\section{MATERIAL E MÉTODOS}

O presente trabalho foi realizado através da revisão de literatura especializada por abordagem indutiva, por meio de técnica de documentação bibliográfica.

Buscaram-se artigos científicos indexados na base de dados bibliográficos SCiELO, MEDLINE e Lilacs, no período de janeiro a maio de 2020, publicados a partir do ano 2000. Os descritores utilizados para a busca foram: Fitoterapia; Fitoterapia na Odontologia; 
Fitoterápicos; Fitoterápicos na saúde bucal; Plantas Medicinais na Odontologia, e seus correspondentes em inglês. Foram incluídos, após a leitura de títulos e resumos, os artigos que se inseriam no tema proposto

\section{RESULTADOS E DISCUSSÃO}

Dentre as afecções mais comuns da boca, pode-se citar a cárie dentária, gengivite, herpes simples, estomatite aftosa e candidose. É importante o diagnóstico correto prévio da doença para indicação adequada da planta a ser utilizada. Quando administrados de forma correta, esses fitoterápicos têm contribuído para a melhora do quadro do paciente. ${ }^{8}$

De acordo com a Agência Nacional de Vigilância Sanitária (ANVISA), os fármacos fitoterápicos são preparações adquiridas empregando-se exclusivamente matéria-prima vegetal ativa. Estes podem ser encontrados na forma sólida ou líquida. Dentre as formas líquidas, preparadas com etanol e água, podese citar os xaropes, as tinturas, glicerídeos, óleos medicinais, infusões (ou chás) e sucos de plantas. Já os extratos sólidos, obtidos a partir da evaporação de solventes e processamento de secagem, têm-se os grânulos, as cápsulas, os comprimidos e outros compostos como os géis e as pomadas. ${ }^{4,9}$

Menezes et al. $^{10}$, em entrevistas com profissionais da equipe de saúde, observaram que há interesse desses trabalhadores da saúde na viabilidade do uso das plantas medicinais, pela sua efetividade antimicrobiana, antiinflamatória, cicatrizante, dentre outras. Além do baixo custo e aceitação popular, existe também a probabilidade de apresentar menos efeitos adversos e menor taxa de toxicidade, o que motiva a indústria farmacêutica a produzir esses fármacos. ${ }^{11}$ Nesse sentido, torna-se evidente que 0 reconhecimento dos efeitos farmacológicos e da toxicidade e discutiam as plantas medicinais no uso de patologias odontológicas, priorizando-se os estudos experimentais e/ou ensaios clínicos, nas línguas inglesa e portuguesa.

dos fitoterápicos, em especial de cada bioma brasileiro, por esses profissionais, pode contribuir para intensificar a sua utilização.

Nessa conjuntura, as plantas medicinais mostram-se como alternativa de interesse para a complementação do tratamento. Porém, ao considerar a vasta diversidade de plantas existentes e seus metabólitos secundários com atividades biológicas, pode-se afirmar que a maioria delas não apresentam testes clínicos que comprovem sua eficácia, sendo embasadas apenas em testes laboratoriais. Assim, os fitoterápicos mais utilizados na Odontologia, que apresentam ação consubstanciada por testes clínicos e laboratoriais são: o cravo-daíndia, a camomila, a malva, a romã, a unha-degato e o própolis. ${ }^{9,11}$

Vieira et al. ${ }^{12}$ relataram que a condição mais referida quanto a indicação do uso de plantas foi a odontalgia, seguida da inflamação gengival; sendo também descrito o uso para higiene oral, erupção dentária, cicatrização, úlceras orais e infecções bucais. Ao considerar a dor como o sintoma mais incômodo da cárie dentária, justifica-se o amplo emprego para a odontalgia.

Das espécies vegetais mais empregadas na odontologia, no âmbito do território nacional, destacam-se a Anacardium occidentale (caju roxo) e a Punica granatum (romã), porém não há concordância na indicação popular; uma vez que ao considerar a grande extensão territorial do país, junto às diferenças sócio-econômico-culturais da população pode refletir sobre o valor 
atribuído ao uso de plantas como recurso e/ou indicação terapêutica atribuída a cada espécie. Entretanto, esse tratamento ainda é pouco utilizado. $^{12}$ No estudo de Evangelista et al..$^{13}$, realizado em Manaus, em relação a utilização de fitoterápicos para patologias da cavidade oral, 92,39\% dos usuários entrevistados ainda não usaram essa terapia, e apenas 7,61\% já fizeram esse tipo de tratamento, sendo a casca do caule do cajueiro (Anacardium occidentale) a mais utilizada, com $40 \%$.

Dentre os compostos fenólicos isolados do A. occidentale, foram encontrados ácidos anacárdicos com considerável atividade inibitória contra as bactérias Gram-positivas Streptococcus mutans, Brevibacterium ammoniagenes, Staphylococcus aureus, Bacillus subtilis e Propionibacterium acnes, levando em consideração o comprimento das cadeias alquílicas destes ácidos que influem na atividade, sendo comparado a atividade destas substâncias com a do ácido salićlico. Embora os ácidos anacárdicos apresentem um espectro de atividade limitado contra bactérias, as atividades foram consideravelmente maiores que as apresentadas pelo ácido salicílico. ${ }^{14}$

O Cravo-da-índia (Syzygium aromaticun L.) é cultivado em várias partes do mundo, incluindo o Brasil. É a partir dele que se extrai o eugenol, um óleo essencial com ação antimicrobiana, utilizado em consultórios. Além de ser usado na preparação de cimentos e pastas, à base de óxido de zinco e eugenol, o cravo-da-índia é utilizado também no tratamento de odontalgias, aftas, mau hálito, estomatites e no tratamento de canal, dado o seu potencial anti-inflamatório, analgésico e antisséptico ${ }^{4,9,15}$.

A Camomila (Matricaria recutita L.) é utilizada como coadjuvante no tratamento de inflamações orais, por apresentar propriedades anti-inflamatórias, cicatrizantes, sedativas e antimicrobianas. É usada na formulação de dentrifícios também, com o objetivo de reduzir a halitose e combater a gengivite. ${ }^{4}$

O óleo essencial azuleno que contém álcool sesquiterpeno, alfa-bisabolol, chamazulene e flavonoides, é o responsável pelos efeitos anti-inflamatório e antimicrobiano. Os flavonoides agem inibindo a liberação de histamina, enquanto o bisabolol tem sido apresentado como viabilizador da formação de tecido de granulação na cicatrização de feridas. Entretanto, essa planta pode interagir com anticoagulantes e aumentar o risco de sangramento, bem como estimular ou até prolongaraação depressora do sistemanervoso central quando usados simultaneamente com barbitúricos e outros sedativos. Por isso, o seu uso deve ser ponderado. ${ }^{9}$

No estudo de Albuquerque et al. ${ }^{7}$, o extrato hidroalcoólico de camomila foi testado em linhagens bacterianas do biofilme dental e comparado aos resultados da Clorexidina 0,12\%. Apesar de apresentar atividade antimicrobiana contra todas as linhagens de bactérias testadas, o fitoterápico apresentou menor efetividade em relação a clorexidina a 0,12\%. Assim, sugerese que o extrato da camomila não seja prescrito como um substituto da clorexidina a 0,12\%.

Já em estudos in vivo, Longo e São Dimas ${ }^{16}$ mostraram o efeito da camomila sobre a cicatrização de úlceras que foram induzidas nas línguas de ratos e estavam limitadas a mucosa. O grupo tratado com a aplicação tópica de $0,02 \mathrm{~mL}$ de extrato de camomila a $10 \%$ apresentou melhores resultados, em relação a epitelização e percentual de fibras colágenas após 10 dias. Porém, não houve influência no grau da inflamação e tamanho da ferida.

A Romã (Punica granatum) é comumente utilizada para o tratamento de infecções de garganta, tosse e febre devido as suas atividades anti-inflamatórias e antibacterianas. O tanino é o principal componente responsável por essa propriedade antibacteriana, que faz da romã um fitoterápico eficaz no combate as bactérias do 
biofilme bucal. Esse componente ainda forma complexos com proteínas solúveis e aumenta a lise bacteriana, assim como interferem na aderência bacteriana às superfícies dentais. 4,9,17 Em uma aplicação coadjuvante ao tratamento periodontal convencional, na forma de chips biodegradáveis inseridas em bolsas periodontais, o $P$. granatum apresentou melhora na reparação tecidual. ${ }^{18} \mathrm{O}$ extrato de $P$. granatum ainda apresentou atividade antiviral, inibindo os vírus Herpes Simples, vírus Sindbis e Poliovírus. ${ }^{19}$

Estudos anteriores, como o de Pereira et al. ${ }^{20}$, já mostraram que o extrato hidroalcoólico do epicarpo da romã inibe a formação de biofilme supragengival com a mesma eficiência da clorexidina. A romã ainda é utilizada no tratamento da periodontite em função da sua ação antioxidante e em estomatites como antisséptico. Por suas características, essa espécie promove a regeneração tecidual e modulação da resposta imune ${ }^{9,17}$.

A malva (Malva sylvestris) é conhecida por suas propriedades anti-inflamatórias e antimicrobianas, determinadas pela presença de mucilagens, taninos, óleos essenciais, glicolipídios e flavonoides. Ainda é estudada quanto ao controle do crescimento das bactérias do biofilme dental. É indicada para o tratamento de tosses, enfermidades de garganta e peito, pelo fato de dissolver mucosidades. ${ }^{9,20,21} \mathrm{~A}$ malva ainda é citada como um fator de proteção contra a hepatotoxicidade causada pelo uso excessivo de paracetamol. $\mathrm{O}$ cuidado com a sua prescrição está relacionado com a possibilidade dessa espécie ocasionar reações de hipersensibilidade em indivíduos sensíveis aos compostos presentes na malva. ${ }^{15}$

A Unha-de-gato (Uncaria tomentosa) é o vegetal que apresenta componentes como alcaloides oxíndoles, triterpenos, esteroides vegetais, compostos fenólicos, glicosídeos, tanino e flavonoides que estão relacionados com suas propriedades anti-inflamatórias, anti- neoplásicas, imunoestimulantes, antimicrobianas e antioxidantes. ${ }^{9}$

Herrera et al. ${ }^{22}$ avaliaram a propriedade antimicrobiana in vitro da unhade-gato perante os patógenos endodônticos Enterococcus faecalis, Staphylococcus aureus e Candida albicans. Eles utilizaram, nesse estudo, quatro substâncias auxiliares: o gel de clorexidina a $2 \%$, o gel de unha-de-gato a $2 \%$ (obtido a partir de um extrato liofilizado), o gel contendo clorexidina mais unha-de-gato a $2 \%$ e o gel de hidroxietilcelulose a $1 \%$ (como controle negativo). O gel de clorexidina associado a unha-de-gato a $2 \%$ foi a substância mais eficaz contra E. faecalis e C. Albicans, seguida do gel de clorexidina e do gel unha-de-gato. Assim, os autores concluíram que o gel de unha-degato a $2 \%$ inibe os patógenos endodônticos e que o efeito pode ser aumentado quando está combinado com clorexidina.

A própolis é uma resina produzida por abelhas (Apis melifera) que é bastante conhecida popularmente por não ser tóxica e apresentar propriedades terapêuticas como ações antimicrobiana, anti-inflamatória, antiviral, antioxidante, anestésica, cicatrizante e antisséptica. Na odontologia, a própolis é dispensada na forma de creme dentais, enxaguatórios bucais, pastilhas e pó, e é utilizada no tratamento de vários acometimentos da cavidade bucal. Como antimicrobiano, ela pode ser usada como irrigante intracanal, como agente cariostático e no tratamento da periodontite e candidoses. A ação anti-inflamatória é possível pela presença de flavonoides e ácido cafeico na própolis, pois estes inibem a produção de ácido araquidônico, e assim, a síntese de prostaglandinas. $\mathrm{Na}$ própolis, ainda se encontra o ferro e o zinco que são importantes para a produção do colágeno, além de estimularem vários sistemas enzimáticos e o metabolismo celular. ${ }^{4,9,23}$

Apesar de seus resultados positivos, o uso da própolis deve ser cauteloso e indicado 
por especialista. Parolia et al. ${ }^{24}$ mostraram que se houver interação medicamentosa entre a própolis e outras drogas, como o dissulfiram ou metranidazol, podem ocorrer náuseas e vômitos. Ela ainda pode ser alergênica em algumas pessoas, pela presença do ácido cafeico, que pode apresentar sintomas como aparecimento de erupções cutâneas, inchaço, coceira, lesões de psoríase na pele ou feridas na boca. Pessoas mais vulneráveis a desenvolver essas reações alérgicas são indivíduos que possuem alergia ao pólen; com asma; grávidas, ou que apresentam alergia a picadas de abelha.

A Aroeira-do-Sertão (Myracrodruon urundeuva) foi identificada por Machado et al. ${ }^{25}$ como um produto com atividades antiinflamatória, antimicrobiana e analgésica. O gel a base de alecrim pimenta (Lippia sidoides) com aroeira (Myracrodruon urundeuva) foi testado em modelo animal com indução de periodontite experimental e comprovou-se sua preservação e reabsorção alveolar do osso, com ações anti-inflamatória e antibacteriana. Outro estudo testou o extrato hidroalcóolico da aroeira sobre S. mutans, S. mitis, S. sobrinus e L. casei, contatando propriedades bactericida e bacteriostática, além de apresentar atividade antifúngica sobre $C$. albicans, $C$ tropicalis e $C$. crusei. $^{24,26}$

Outro produto vegetal bastante utilizado no combate a bactérias orais é o alho (Allium sativum). Testado sobre microorganismos cariogênicos e periodontopatogênicos. ${ }^{27,4}$ Brakri e Douglas ${ }^{27}$ observaram que o alho reduziu o crescimento bacteriano da Porphiromonas gingivalis (uma bactéria bastante presente na doença periodontal) através da inibição da tripsina e da protease, mostrando-se bastante importante na terapêutica periodontal. Outro estudo, porém, mostra que há uma diminuição do número de bactérias "protetoras" quando os pacientes são submetidos ao uso de enxaguatórios com esse componente. ${ }^{4}$
Alguns fitoterápicos são incorporados a dentrifícios, como a babosa (Aloe vera), que é ressaltada por suas propriedades anti-inflamatória e antisséptica, e pela disponibilização de elementos nutricionais que atuam sinergicamente nos tecidos epiteliais e no sistema imune, agindo de forma antimicrobiana, favorecendo o crescimento celular e, consequente, recuperação do tecido agredido. ${ }^{4} \mathrm{~A}$ combinação da babosa e o extrato hidroalcóolico de própolis foi capaz de acelerar a reparação de feridas em ratos, o que atrai ainda mais o seu uso na odontologia. ${ }^{27,28}$

Outros extratos hidrooalcoólicos de folha e/ou casca de algumas plantas foram avaliados a fim de se analisar suas atividades antimicrobianas frente aos microorganismos cariogênicos da cavidade bucal. Foram testados os extratos de Schinus terebintifolius Raddi (aroeira da praia), Syderoxylon obtusifolium (quixabeira), Bauhínia forficata Linn (mororó), Anadenanthera colubrina Brenan (angico), Spondias tuberosa Arruda (umbuzeiro), Tabebuia pentaphylla Vell (ipê rosa) e Guapira opposita Vell (João mole) em cepas de Streptococcus mutans, S. salivarius, S. oralis e S. parasanguis, e observaram que todas as espécies de Streptococcus analisadas apresentaram sensibilidade a, pelo menos, um tipo de extrato vegetal. A S. mutans, principal patógeno da cárie dentária, apresentou considerável sensibilidade aos extratos vegetais testados. Quanto ao S. oralis, apenas os extratos de S. terebintifolius, S. obtusifolium e A. colubrina Brenan demonstraram capacidade de combatê-lo. ${ }^{29}$

A S. salivarius mostrou-se sensível a todos os extratos, exceto ao extrato da casca do $A$. colubrina, enquanto que a S. parasanguis apresentou resistência a maioria dos extratos analisados, com sensibilidade apenas para os extratos de $S$. tuberosa e de T. pentaphylla. O que é relevante, uma vez que esta espécie tem papel importante na prevenção do 
biofilme dental, por atuar como antagonista das bactérias responsáveis por este processo. Salienta-se o potencial de $S$. terebintifolius e $S$. obtusifolium contra todos os estreptococos estudados envolvidos na patogênese da cárie, mesmo em concentrações baixas, além de não apresentar ação antimicrobiana para o S. parasanguis. Essas evidências podem ser fundamentadas por essas plantas possuírem metabólitos secundários, como os flavonoides e saponinas, que conferem essa atividade antimicrobiana. Contudo, são necessários estudos "in vivo", que testem esses comportamentos reais nas condições da

\section{cavidade oral. ${ }^{29}$}

Não obstante os estudos comprovem a eficácia da fitoterapia na odontologia, é preciso fazer o uso desta de forma cautelosa e com responsabilidade, de posse do conhecimento científico. O cirurgiãodentista necessita usar as plantas medicinais conscientemente e, para isso, é preciso a inserção da fitoterapia como componente curricular obrigatório na graduação dos cursos de Odontologia. As plantas medicinais surgem como uma alternativa eficiente e de custo mais acessível às comunidades carentes.

\title{
CONSIDERAÇÕES FINAIS
}

Conforme a literatura revisada, os fitoterápicos podem contribuir para a prevenção, controle e tratamento de várias doenças bucais, podendo ser usados concomitantes a medicamentos tradicionais (alopáticos) ou não. No entanto, é importante que o profissional conheça a ação farmacológica desses compostos fitoterápicos, bem como os seus efeitos colaterais, interações medicamentosas e as contraindicações. Uma vez, bem indicados e administrados com discernimento, eles precisam e podem ser aplicados na Odontologia.

\section{USE OF MEDICINAL PLANTS IN DENTISTRY: A BIBLIOGRAPHIC REVIEW}

\begin{abstract}
Phytotherapy has gained ground in the dentistry field because it presents natural products with high therapeutic activity, less toxicity and better scientifically proven biocompatibility, when compared to conventional medicines. The lack of knowledge about indications and care in the use of medicinal plants is still a problem among health professionals. Specifically, in dentistry, this practice has been little explored for the treatment of oral disorders or systemic diseases with oral manifestations. The purpose of this study was to review and synthesize the information in the scientific literature on medicinal plants that are most used for oral cavity problems, in order to contribute and promote the use of this therapy by dentists. The present work was carried out through the review of specialized literature using an inductive approach, using the technique of bibliographic documentation. Herbal medicines are able to contribute to the prevention, control and treatment of various oral diseases, and can be used simultaneously with traditional (allopathic) medicines or not. However, it is important that the professional knows the pharmacological
\end{abstract}


action of these herbal compounds, as well as their side effects, drug interactions and contraindications.

KEYWORDS: Phytotherapy. Dentistry. Oral Pathologies.

\section{REFERÊNCIAS}

1. Brasil, Saúde dd. Portaria n. ${ }^{\circ} 971$, de 03 de maio de 2006. Aprova a Política Nacional de Práticas Integrativas e Complementares (PNPIC) no Sistema Único de Saúde. Diário Oficial da União. 2006; 84.

2. Santos EB, Dantas GS, Santos HB, Diniz M, Sampaio FC. Estudo etnobotânico de plantas medicinais para problemas bucais no município de João Pessoa, Brasil. Rev. Bras. Farmacogn. 2009; 19(1B): 321-24.

3. Nascimento Júnior B, Tínel L, Silva E, Rodrigues LA, Freitas TON, Nunes XP, et al. Avaliação do conhecimento e percepção dos profissionais da estratégia de saúde da família sobre o uso de plantas medicinais e fitoterapia em Petrolina-PE, Brasil. Rev Bras Plantas Med. 2016; 18(1): 57-66.

4. Francisco K. Fitoterapia: uma opção para o tratamento odontológico. Revista Saúde. 2010; 4(1): 18-24.

5. Silva JMD, Verçosa BMG, Nobre FC, Azevedo LM, Silva MLT, Belo ZS, et al. Utilization of phytotherapics in Dentistry: integrative review. Research, Society and Development. 2020; 9(8): 1-17.

6. Brasil, Ministério da Saúde. Política Nacional de Práticas Integrativas e Complementares no SUS - PNPIC-SUS. Brasília: Ministério da Saúde, 2005. 91p.

7. Albuquerque $A C L$, Pereira MDSV, Pereira JV, Costa MRM, Pereira LF, Higino JS. Efeito antimicrobiano do extrato da Matricaria recutita
Linn. (camomila) sobre microrganismos do biofilme dental. Pesqui. Bras. Odontopediatria Clín. Integr. 2010; 10(3): 451-55.

8. Bohneberger G, Machado MA, Debiasi MM, Dirschnabel AJ, Oliveira Ramos G. Fitoterápicos na odontologia, quando podemos utilizá-los? / Phytotherapy in dentistry, when can we use them? Braz. J. Hea. Rev. 2019; 2(4): 3504-17.

9. Aleluia CDM, Procópio VDC, Oliveira MTG, Furtado PGS, Giovannini JFG, Mendonça SMSD. Fitoterápicos na odontologia. Rev Odontol Univ Cid São Paulo (Online). 2015;27(2): 126-34.

10. Menezes VA, dos Anjos AGP, Pereira MR, Leite AF, Granville-Garcia AF. Terapêutica com plantas medicinais: percepção de profissionais da estratégia de saúde da família de um município do agreste pernambucano. Rev. Odonto. 2012; 1(1): 111-22.

11. Monteiro MHDA, Magalhães-Fraga SAP. Fitoterapia na odontologia: levantamento dos principais produtos de origem vegetal para saúde bucal. Rev Fitos, 2015; 9(4): 265-68.

12. Vieira $D$, Amaral $F$, Maciel $M$, Nascimento FF, Libério A. Plantas e constituintes químicos empregados em Odontologia: revisão de estudos etnofarmacológicos e de avaliação da atividade antimicrobiana in vitro em patógenos orais. Rev Bras Plantas Med. 2014; 16(1): 135-67.

13. Evangelista S, Sampaio F, Parente R, Bandeira M. Fitoterápicos na odontologia: estudo etnobotânico na cidade de Manaus. Rev Bras 
Plantas Med. 2013; 15(4): 513-19.

14. Correia SDJ, David JP, David JM. Metabólitos secundários de espécies de Anacardiaceae. Rev Quím. Nova. 2006; 29(6): 1287-300.

15. Ildefonso Junior J, Monteiro AB. Plantas medicinais e fitoterápicos úteis na odontologia clínica: uma Revisão. Rev Fac Odontol Univ Fed Bahia. 2020; 50(1): 47-56.

16. Longo R, São Dimas J. Effects of Chamomilla recutita (L.) on oral wound healing in rats. Cir Bucal. 2011; 16(6): 716-21.

17. Werkman C, Granato D, Kerbauy W, Sampaio F, Brandão A, Rode S. Aplicações terapêuticas da Punica granatum L.(romã). Rev Bras Plantas Med. 2008; 10(3): 104-11.

18. Sastravaha G, Yotnuengnit P, Booncong $P$, Sangtherapitikul P. Adjunctive periodontal treatment with Centella asiatica and Punica granatum extracts. A preliminary study. J Int Acad Periodontol. 2003; 5(4): 106-15.

19. Mouhajir F, Hudson J, Rejdali M, Towers G. Multiple antiviral activities of endemic medicinal plants used by Berber peoples of Morocco. Pharm. biol. 2001; 39(5): 364-74.

20. Pereira JV, Pereira MSV, Sampaio FC, Sampaio MCC, Alves PM, Araújo CRF, et al. Efeito antibacteriano e antiaderente in vitro do extrato da Punica granatum Linn. sobre microrganismos do biofilme dental. Rev Bras Farmacogn. 2006; 16(1): 88-93.

21. Buffon MDCM, da Costa Lima ML, Galarda I, Cogo L. Avaliação da eficácia dos extratos de Malva sylvestris, Calêndula officinalis, Plantago major e Curcuma zedoarea no controle do crescimento das bactérias da placa dentária. Estudo in vitro. Rev Visão Acadêmica. 2001; 2(1): 31-38.
22. Herrera DR, Tay LY, Rezende EC, Kozlowski Jr VA, dos Santos EB. In vitro antimicrobial activity of phytotherapic Uncaria tomentosa against endodontic pathogens. J Oral Sci. 2010; 52(3): 473-76.

23. Barrientos L, Herrera CL, Montenegro G, Ortega X, Veloz J, Alvear M, et al. Chemical and botanical characterization of Chilean propolis and biological activity on cariogenic bacteria Streptococcus mutans and Streptococcus sobrinus. Braz. J. Microbiol. 2013; 44(2): 577-85.

24. Parolia A, Thomas MS, Kundabala M, Mohan M. Propolis and its potential uses in oral health. Int. J. Med. Sci. 2010; 2(7): 210-15.

25. Machado AC, Freitas AD, Sales-Peres SH. Atividade anti-inflamatória de produtos naturais em Odontologia: uma revisão sistemática. Rev Fitos. 2016; 10(1): 47-58.

26. Alves PM, Queiroz LMG, Pereira JV, Pereira MSV. Atividade antimicrobiana, antiaderente e antifúngica in vitro de plantas medicinais brasileiras sobre microrganismos do biofilme dental e cepas do gênero Candida. Rev Soc Bras Med Trop. 2009; 42(2): 222-24.

27. Bakri I, Douglas C. Inhibitory effect of garlic extract on oral bacteria. Arch. Oral Biol. 2005; 50(7): 645-51.

28. Semenoff Segundo A, Bosco A, Maia D, Ribeiro RV, Aguiar LBH, Rocatto GEGD, et al. Influência do Aloe vera e própolis na contração de feridas em dorso de ratos. Rev Periodontia. 2007; 17(1): 23-28.

29. Rocha EAL, de Carvalho AVO, de Andrade SRA, Trovão DM, Medeiros ACD, Costa EMMB. Atividade Antimicrobiana "In Vitro" de Extratos Hidroalcoólicos de Plantas Medicinais do Nordeste Brasileiro em Bactérias do Gênero Streptococcus. Pesqui. Bras. Odontopediatria Clín. Integr. 2013; 13(3): 233-38. 